\title{
Harmonious Coloring of Central Graphs of
}

\section{Certain Snake Graphs}

\author{
M. S. Franklin Thamil Selvi \\ Sathyabama University, Chennai, India
}

\begin{abstract}
Copyright (C) 2014 M. S. Franklin Thamil Selvi. This is an open access article distributed under the Creative Commons Attribution License, which permits unrestricted use, distribution, and reproduction in any medium, provided the original work is properly cited.
\end{abstract}

\begin{abstract}
A harmonious coloring of a simple graph is the proper vertex coloring such that each pair of colors appears together on at most one edge. The harmonious chromatic number of $G$, denoted by $\chi_{\mathrm{h}}(\mathrm{G})$, is the least number of colors in a harmonious coloring of $G$. The paper gives the structural properties and the estimates of harmonious chromatic number of central graphs of Triangular snake graph $C\left[T_{n}\right]$, Double triangular snake graph $C\left[D\left(T_{n}\right)\right]$ and Diamond snake graph $\mathrm{C}\left[\mathrm{D}_{\mathrm{n}}\right]$.
\end{abstract}

Keywords: Harmonious coloring, Central graph, Triangular snake, Double triangular snake, Diamond snake

\section{Introduction}

Graph Theory is one of the most developing branches of mathematics with wide applications to computer science. Graph Theory is applied in diverse areas such as social sciences, linguistics, physical sciences, communication engineering and others. Graph coloring is one of the oldest and an interesting problem that comes up in lots of applications. Graph coloring is an assignment of colors (or any distinct marks) to the vertices of a graph. A vertex coloring is called proper coloring if no two adjacent vertices of the graph receive the same color and the graph is then called properly colored graph. Many problems can be formulated as a graph coloring problem including time tabling, scheduling, register allocation, channel assignment in radio stations such that no station has a conflict.

There are many problems in graph coloring, one such problem is harmonious coloring problem. A harmonious coloring of a simple graph is the proper vertex 
coloring such that each pair of colors appears together on at most one edge. The harmonious chromatic number of $G$, denoted by $\chi_{\mathrm{h}}(\mathrm{G})$, is the least number of colors in a harmonious coloring of $G$. This problem has potential application in communication networks, for example transportation networks, computer networks, airway network system, satellite navigation system, radio navigation system etc. In radio navigation it is used as a guiding system in bad weather condition or in case of invisibility of distance objects. It is also used to calculate the address of the block in which the desired record is placed. Harmonious coloring was first introduced by Frank Harray and M. J. Plantholt in 1982. However the proper definition of this notion is due to Lee Hopcroft and Krishnamoorty [1]. The harmonious chromatic number of several different families of graph has been found by different author. The lower bound of harmonious chromatic number may be considered as an edge receiving a unique color pair. Moreover if $|\mathrm{E}(\mathrm{G})| \leq \mathrm{kC}_{2}$ then a graph is harmoniously colored with $\mathrm{k}$ colors. Paths and cycles were the first graphs whose harmonious chromatic numbers have been established. It was shown by Hopcroft and Krishnamoorthy [1] that the problem of determining the harmonious chromatic number of a graph is Np-hard. Moreover Keith Edwards and Mc Diarmid [2] showed that the problem remains hard even restricted to the class of trees.

\section{Preliminaries}

A graph $\mathrm{G}$ is a finite non-empty set $\mathrm{V}(\mathrm{G})$ of elements called vertices (or points) and set $E(G)$ of unordered pair of distinct elements of $V(G)$ called edges (or lines). An edge of a graph which joins vertex to itself is called a loop. And if some pairs of vertices are joined by more than one edge, such edges are called parallel edges. A graph $\mathrm{G}$ is said to be connected if there is a path between any two of its vertices. The graphs considered in this paper are simple connected graphs.

\section{Overview of the paper}

The central graph of any graph $G$ is obtained by subdividing each edge of $G$ exactly once and joining all the non-adjacent vertices of $G$. This paper gives the structural properties and the exact harmonious chromatic number of central graphs of Triangular snake graph $C\left[T_{n}\right]$, Double triangular snake graph $C\left[D\left(T_{n}\right)\right]$ and Diamond snake graph $\mathrm{C}\left[\mathrm{D}_{\mathrm{n}}\right]$.

Proposition 1[2]: Let $G$ be a simple connected graph. Then the harmonious chromatic number $\chi_{h}(\mathrm{G})$ satisfies $\chi_{h}(\mathrm{G}) \geq \Delta(\mathrm{G})+1$, where $\Delta(\mathrm{G})$ is the maximum degree of vertices of $\mathrm{G}$.

Proposition 2[2]: For any graph $G$ with $m$ edges $\chi_{h}(G) \geq Q(m)$, where $Q(m)=$ $\left.\Gamma\left(1+(8 \mathrm{~m}+1)^{1 / 2}\right) / 2\right\rceil$. 


\section{Main result}

Definition 4.1.1: $\quad$ A triangular cactus is a connected graph all of whose blocks are triangles. A triangular snake is a triangular cactus whose block-cut point graph is a path. Equivalently it is obtained from a path $P=v_{1}, v_{2}, \ldots \ldots v_{n+1}$ by joining $v_{i}$ and $\mathrm{v}_{\mathrm{i}+1}$ to a new vertex $\mathrm{u}_{1}, \mathrm{u}_{2}, \mathrm{u}_{3}, \ldots \ldots, \mathrm{u}_{\mathrm{n}}$. A triangular snake has $2 \mathrm{n}+1$ vertices and $3 n$ edges, where $n$ is the number of blocks in the triangular snake. We denote this snake by $\mathrm{T}_{\mathrm{n}}$.

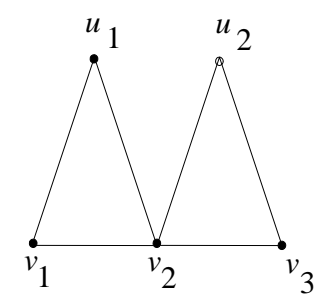

Figure: 1 Triangular snake graph $\mathrm{T}_{2}$

\section{Structural Properties of Central Graph of Triangular Snake:}

Let $T_{n}$ be the triangular snake graph with $2 n+1$ vertices and $3 n$ edges.

Maximum degree $\Delta\left[\mathrm{T}_{\mathrm{n}}\right]=4$

Minimum degree $\delta\left[\mathrm{T}_{\mathrm{n}}\right]=2$

Number of vertices in $C\left[T_{n}\right]=5 n+1$

Number of edges in $C\left[T_{n}\right]=2 n^{2}+4$

Maximum degree $\Delta\left\{\mathrm{C}\left[\mathrm{T}_{\mathrm{n}}\right]\right\}=2 \mathrm{n}$

Minimum degree $\delta\left\{C\left[T_{n}\right]\right\}=2$

\section{Theorem 4.2.1:}

The harmonious chromatic number of central graph of triangular snake $C\left[T_{n}\right]$ is $\Delta\left\{\mathrm{C}\left[\mathrm{T}_{\mathrm{n}}\right]\right\}+3$.

(ie) $\chi_{h}\left(C\left[T_{n}\right]\right)=\Delta\left\{C\left[T_{n}\right]\right\}+3$

\section{Proof:}

Let $T_{n}$ be the triangular snake graph with $2 n+1$ vertices and $3 n$ edges. Let $\left\{v_{1}\right.$, $\mathrm{v}_{2}, \ldots \ldots, \mathrm{v}_{\mathrm{n}+1}, \mathrm{u}_{1}, \mathrm{u}_{2}, \mathrm{u}_{3}, \ldots ., \mathrm{u}_{\mathrm{n}\}}$. Be the vertices of the triangular snake $\mathrm{T}(\mathrm{n})$.

Now by definition of central graph, each edge of graph is subdivided by a new vertex. Therefore assume that each edge $\left(v_{i}, v_{i+1}\right)$ and the line joining $v_{i}$ and $v_{i+1}$ to a vertex $u_{i}, i=1,2,3, \ldots, n$ are subdivided by the vertices $w_{i}, e_{j j}$, and $e_{j, j+1}, j=$ $1,2,3, \ldots, \mathrm{n}$ respectively. 
Assign coloring $\mathrm{c}$ to the vertices as follows:

$\mathrm{c}\left(\mathrm{v}_{\mathrm{i}}\right)=\mathrm{i}$ for $1 \leq \mathrm{i} \leq \mathrm{n}+1$

$\mathrm{c}\left(\mathrm{u}_{\mathrm{i}}\right) \& \mathrm{c}\left(\mathrm{w}_{\mathrm{i}}\right)=(\mathrm{n}+1)+\mathrm{i}$ for $1 \leq \mathrm{i} \leq \mathrm{n}$

$\mathrm{c}\left(\mathrm{e}_{\mathrm{jj}}\right)=(2 \mathrm{n}+1)+1$ for $1 \leq \mathrm{j} \leq \mathrm{n}$

$c\left(e_{j, j+1}\right)=(2 n+2)+1$ for $1 \leq j \leq n$

clearly c is a $2 n+3$ coloring.

First claim that $\mathrm{c}$ is a proper coloring.

Since each $\mathrm{c}\left(\mathrm{v}_{\mathrm{i}}\right), \mathrm{c}\left(\mathrm{u}_{\mathrm{i}}\right)$ and its neighbours receive distinct colors. Further $\mathrm{c}\left(\mathrm{v}_{\mathrm{i}}\right) \neq$ $\mathrm{c}\left(\mathrm{u}_{\mathrm{i}}\right)$. Hence $\mathrm{c}$ is a proper coloring.

Next we claim that $\mathrm{c}$ is harmonious coloring. It is clear that each vertex receive a distinct color at a distance at most 2 from all other vertices, thus coloring is harmonious.

Finally we claim that $\mathrm{c}$ is the minimum number of colors in a harmonious coloring. Suppose not, we have the following cases.

Case (i): The color set $\mathrm{c}\left(\mathrm{v}_{\mathrm{i}}\right)$ and $\mathrm{c}\left(\mathrm{u}_{\mathrm{i}}\right)$ contains $2 \mathrm{n}+1$ colors. If we assign $2 \mathrm{n}$ colors, then the color pair will not be distinct which contradict the definition of harmonious colors.

Case (ii): The neighbours of $u_{i}$ and $v_{i}$ are given same color, then the color pair repeats which is a contradiction to the definition of harmonious coloring.

Hence the minimum number of colors in a harmonious coloring for central graph of triangular snake is $2 n+3$, where $2 n$ is the maximum degree in $C\left(T_{n}\right)$.

Hence $\chi_{h}(G)=\Delta\left\{C\left[T_{n}\right]\right\}+3$.

\section{Illustration for the above theorem:}

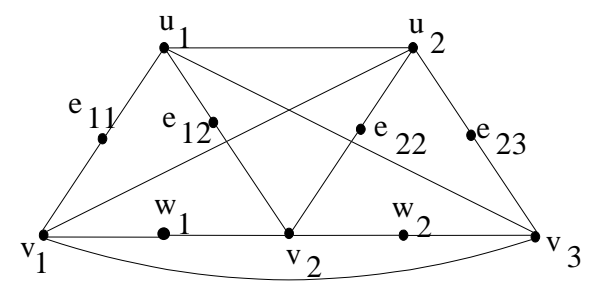

Figure: 2 Central graph of triangular snake $\mathrm{C}\left[\mathrm{T}_{2}\right]$

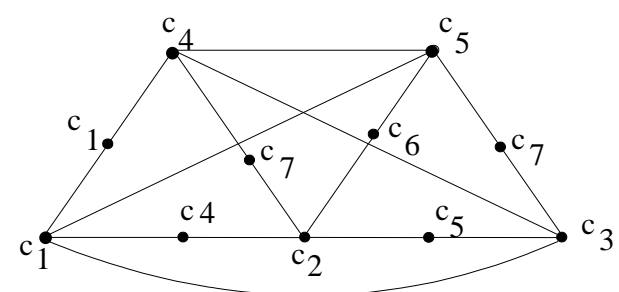

Figure: $3 \chi_{\mathrm{h}}\left(\mathrm{C}\left[\mathrm{T}_{2}\right]\right)=7$ 
Definition 4.2.2: $\quad$ A double triangular snake $D\left[T_{n}\right]$ consists of two triangular snakes that have a common path. That is, a double triangular snake is obtained from a path $\mathrm{v}_{1}, \mathrm{v}_{2} \ldots \mathrm{v}_{\mathrm{n}+1}$ by joining $v_{i}$ and $v_{i+1}$ to a new vertex $w_{i}$ and to a new vertex $u_{i}$ for $1 \leq i \leq \mathrm{n}$.

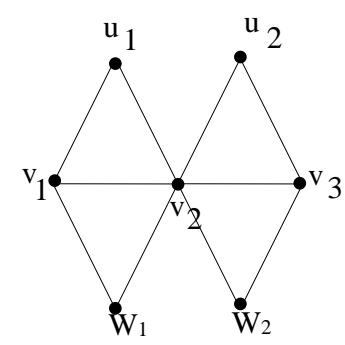

Figure: 4 Double triangular snake $D\left[T_{5}\right]$

\section{Structural Properties of Central Graph of Double Triangular Snake}

Let $\mathrm{D}\left(\mathrm{T}_{\mathrm{n}}\right)$ be the double triangular snake graph with $3 \mathrm{n}+1$ vertices and $5 \mathrm{n}$ edges.

Maximum degree $\Delta\left[\mathrm{D}\left(\mathrm{T}_{\mathrm{n}}\right)\right]=6$

Minimum degree $\delta\left[\mathrm{D}\left(\mathrm{T}_{\mathrm{n}}\right)\right]=2$

Number of vertices in

$\mathrm{C}\left[\mathrm{D}\left(\mathrm{T}_{\mathrm{n}}\right)\right]=8 \mathrm{n}+1$

Number of edges in

$\mathrm{C}\left[\mathrm{D} \mathrm{T}_{\mathrm{n}}\right)=\left(9 \mathrm{n}^{2}+13 \mathrm{n}\right) / 2$

Maximumdegree $\Delta\left\{C\left[D\left(T_{n}\right)\right]=3 n\right.$

Minimum degree $\delta\left\{C\left[D\left(T_{n}\right)\right]=2\right.$

\section{Theorem 4.2.2:}

The harmonious chromatic number of central graph of double triangular snake graph $C\left[D\left(T_{n}\right)\right]$ is

$\Delta\left\{\mathrm{C}\left[\mathrm{D}\left(\mathrm{T}_{\mathrm{n}}\right)\right]\right\}+5$.

(ie) $\chi_{h}\left(C\left[D\left(T_{n}\right)\right]\right)=\Delta\left\{C\left[D\left(T_{n}\right)\right]\right\}+5$.

\section{Proof:}

Let $\mathrm{D}\left(\mathrm{T}_{\mathrm{n}}\right)$ be the double triangular snake graph with $3 \mathrm{n}+1$ vertices and $5 \mathrm{n}$ edges. Let $\left\{\mathrm{v}_{1}, \mathrm{v}_{2}, \ldots, \mathrm{v}_{\mathrm{n}+1}, \mathrm{u}_{1}, \mathrm{u}_{2}, \mathrm{u}_{3}, \ldots, \mathrm{u}_{\mathrm{n}}, \mathrm{w}_{1}, \mathrm{w}_{2}, \ldots, \mathrm{w}_{\mathrm{n}}\right\}$ be the vertices of the double triangular snake graph $\mathrm{D}\left(\mathrm{T}_{\mathrm{n}}\right)$.

Now by definition of central graph, each edge of graph is subdivided by a new vertex. Therefore assume that each edge $\left(\mathrm{v}_{\mathrm{i}}, \mathrm{v}_{\mathrm{i}+1}\right),\left(\mathrm{u}_{\mathrm{i}}, \mathrm{v}_{\mathrm{j}}\right)$ and $\left(\mathrm{v}_{\mathrm{j}}, \mathrm{w}_{\mathrm{i}}\right) \mathrm{i}=1,2, \ldots, \mathrm{n}$ and $\mathrm{j}=1,2, \ldots, \mathrm{n}+1$ is subdivided by the vertices $\mathrm{x}_{\mathrm{i}}$, $\mathrm{e}_{\mathrm{ij}}$ and $\mathrm{f}_{\mathrm{ij}}$ for $\mathrm{i}=1,2,3, \ldots . . \mathrm{n}$ and $\mathrm{j}=1,2,3, \ldots . . \mathrm{n}+1$ respectively. 
Assign coloring c to the vertices as follows:

$\mathrm{c}\left(\mathrm{v}_{\mathrm{i}}\right)=\mathrm{i}$ for $1 \leq \mathrm{i} \leq \mathrm{n}+1$

$\mathrm{c}\left(\mathrm{u}_{\mathrm{i}}\right)=(\mathrm{n}+1)+\mathrm{i}$ for $1 \leq \mathrm{i} \leq \mathrm{n}$

$\mathrm{c}\left(\mathrm{w}_{\mathrm{j}}\right) \& \mathrm{c}\left(\mathrm{x}_{\mathrm{i}}\right)=(2 \mathrm{n}+1)+\mathrm{i}$ for $1 \leq \mathrm{i} \leq \mathrm{n}$

$\mathrm{c}\left(\mathrm{e}_{\mathrm{j}, \mathrm{j}}\right)=(3 \mathrm{n}+1)+1$ for $1 \leq \mathrm{j} \leq \mathrm{n}$

$c\left(e_{j, j+1}\right)=(3 n+2)+1$ for $1 \leq j \leq n$

$c\left(f_{j, j}\right)=(3 n+3)+1$ for $1 \leq \mathrm{j} \leq \mathrm{n}$

$\mathrm{c}\left(\mathrm{f}_{\mathrm{j}, \mathrm{j}}\right)=(3 \mathrm{n}+4)+1$ for $1 \leq \mathrm{j} \leq \mathrm{n}$

clearly c is a $3 n+5$ coloring.

First claim that $\mathrm{c}$ is a proper coloring:

Since each $\mathrm{c}\left(\mathrm{v}_{\mathrm{i}}\right), \mathrm{c}\left(\mathrm{u}_{\mathrm{i}}\right), \mathrm{c}\left(\mathrm{w}_{\mathrm{i}}\right)$ and its neighbours receive distinct colors. Further $\mathrm{c}\left(\mathrm{v}_{\mathrm{i}}\right) \neq \mathrm{c}\left(\mathrm{u}_{\mathrm{i}}\right) \neq \mathrm{c}\left(\mathrm{w}_{\mathrm{i}}\right)$. The coloring $\mathrm{c}$ is a proper coloring.

Next claim that $\mathrm{c}$ is harmonious coloring. It is clear that each vertex receive a distinct color at a distance atmost 2 from all other vertices, thus coloring is harmonious.

Now we claim that $\mathrm{c}$ is the minimum number of colors in a harmonious coloring. Suppose not, we have the following cases.

Case (i): The color set $\mathrm{c}\left(\mathrm{v}_{\mathrm{i}}\right), \mathrm{c}\left(\mathrm{u}_{\mathrm{i}}\right)$ and $\mathrm{c}\left(\mathrm{w}_{\mathrm{i}}\right)$ contains $3 \mathrm{n}+1$ colors. If we assign $3 \mathrm{n}$ colors, then the color pair will not be distinct which contradict the definition of harmonious colors.

Case (ii): The neighbours of $u_{i}, v_{i}$ and $w_{i}$ are given same color, then the color pair repeats which is a contradiction to the definition of harmonious coloring.

Hence the minimum number of colors in a harmonious coloring for central graph of double triangular snake is $3 n+5$, where $3 n$ is the maximum degree in $C\left[D\left(T_{n}\right)\right]$. Hence $\chi_{\mathrm{h}}(\mathrm{G})=\Delta\left\{\mathrm{C}\left[\mathrm{D}\left(\mathrm{T}_{\mathrm{n}}\right)\right]\right\}+5$.

\section{Illustration for the above theorem:}

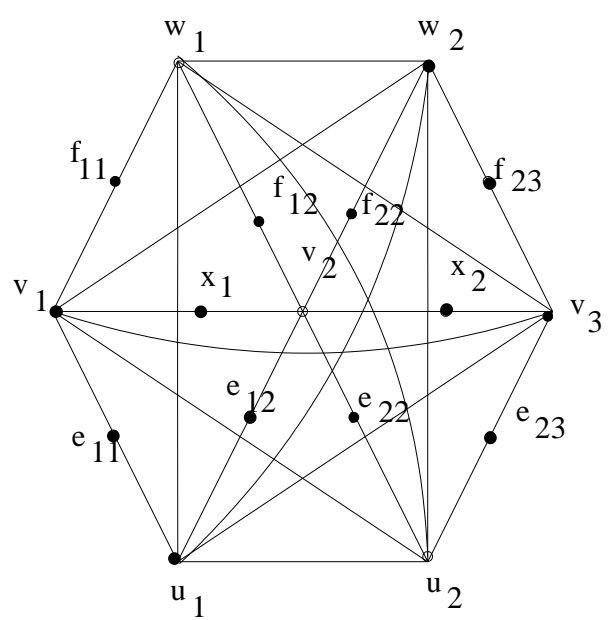

Figure 5: Central graph of double triangular snake C [D $\left.\left(\mathrm{T}_{2}\right)\right]$ 


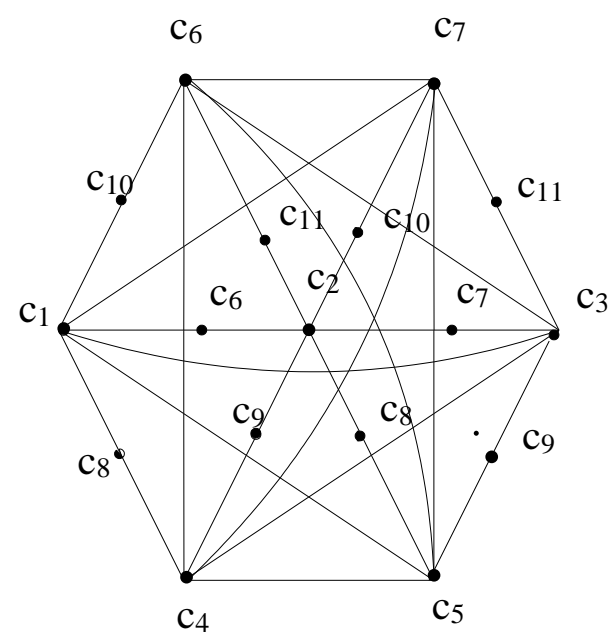

Figure 6: $\chi_{\mathrm{h}}\left(\mathrm{C}\left[\mathrm{D}\left(\mathrm{T}_{2}\right)\right]\right)=11$

Definition 4.2.3: A diamond snake graph is obtained by joining vertices $v_{i}$ and $v_{i+1}$ to two new vertices $u_{i}$ and $w_{i}$ for $i=1,2,3, \ldots \ldots, n-1$. A diamond snake has $3 n+1$ vertices and $4 n$ edges, where $n$ is the number of blocks in the diamond snake. We denote this snake by $\mathrm{D}_{\mathrm{n}}$.

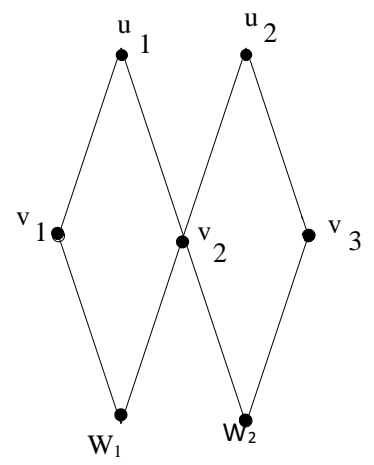

Figure 7: diamond snake graph $\mathrm{D}_{2}$

\section{Structural Properties of Central Graph of Diamond Snake:}

Let $D_{n}$ be the diamond snake graph with $3 n+1$ vertices and $4 n$ edges.

Maximum degree $\Delta\left[\mathrm{D}_{\mathrm{n}}\right]=4$

Minimum degree $\delta\left[\mathrm{D}_{\mathrm{n}}\right]=2$

Number of vertices in $C\left[D_{n}\right]=7 n+1$

Number of edges in $C\left[D_{n}\right]=\left(9 n^{2}+11 n\right) / 2$

Maximum degree $\Delta\left\{C\left[D_{n}\right]=3 n\right.$

Minimum degree $\delta\left\{C\left[D_{n}\right]\right\}=2$ 


\section{Theorem 4.2.3:}

The harmonious chromatic number of central graph of diamond snake graph $\mathrm{C}\left[\mathrm{D}_{\mathrm{n}}\right]$ is $\Delta\left\{\mathrm{C}\left[\mathrm{D}_{\mathrm{n}}\right]\right\}+5$, for $\mathrm{n}>1$. (ie) $\chi_{\mathrm{h}}\left(\mathrm{C}\left[\mathrm{D}_{\mathrm{n}}\right]\right)=\Delta\left\{\mathrm{C}\left[\mathrm{D}_{\mathrm{n}}\right]\right\}+5$, forn $>1$.

\section{Proof:}

Let $D_{n}$ be the diamond snake graph with $3 n+1$ vertices and $4 n$ edges. Let $\left\{\mathrm{v}_{1}, \mathrm{v}_{2}, \ldots, \mathrm{v}_{\mathrm{n}+1}, \mathrm{u}_{1}, \mathrm{u}_{2}, \mathrm{u}_{3}, \ldots, \mathrm{u}_{\mathrm{n}}, \mathrm{w}_{1}, \mathrm{w}_{2}, \ldots, \mathrm{w}_{\mathrm{n}}\right\}$ be the vertices of the diamond snake $\mathrm{D}_{\mathrm{n}}$.

Now by definition of central graph, each edge of graph is subdivided by a new vertex. Therefore assume that each edge $\left(u_{i}, v_{j}\right)$ and $\left(v_{j}, w_{i}\right) i=1,2, \ldots, n$ and $\mathrm{j}=1,2, \ldots, \mathrm{n}+1$ is subdivided by the vertices $e_{i j}$ and $f_{i j}$ for $i=1,2,3, \ldots . . n$ and $\mathrm{j}=1,2,3, \ldots \ldots \mathrm{n}+1$ respectively.

Assign coloring $\mathrm{c}$ to the vertices as follows:

$\mathrm{c}\left(\mathrm{v}_{\mathrm{i}}\right)=\mathrm{i}$ for $1 \leq \mathrm{i} \leq \mathrm{n}+1$

$\mathrm{c}\left(\mathrm{u}_{\mathrm{i}}\right)=(\mathrm{n}+1)+\mathrm{i}$ for $1 \leq \mathrm{i} \leq \mathrm{n}$

$\mathrm{c}\left(\mathrm{w}_{\mathrm{j}}\right)=(2 \mathrm{n}+1)+\mathrm{i}$ for $1 \leq \mathrm{i} \leq \mathrm{n}$

$c\left(e_{j, j}\right)=(3 n+1)+1$ for $1 \leq j \leq n$

$c\left(e_{j, j+1}\right)=(3 n+2)+1$ for $1 \leq j \leq n$

$\mathrm{c}\left(\mathrm{f}_{\mathrm{j}, \mathrm{j}}\right)=(3 \mathrm{n}+3)+1$ for $1 \leq \mathrm{j} \leq \mathrm{n}$

$\mathrm{c}\left(\mathrm{f}_{\mathrm{j}, \mathrm{j}}\right)=(3 \mathrm{n}+4)+1$ for $1 \leq \mathrm{j} \leq \mathrm{n}$

clearly $\mathrm{c}$ is a $3 \mathrm{n}+5$ coloring.

First claim that $\mathrm{c}$ is a proper coloring:

Since each $\mathrm{c}\left(\mathrm{v}_{\mathrm{i}}\right), \mathrm{c}\left(\mathrm{u}_{\mathrm{i}}\right), \mathrm{c}\left(\mathrm{w}_{\mathrm{i}}\right)$ and its neighbours receive distinct colors. Further $\mathrm{c}\left(\mathrm{v}_{\mathrm{i}}\right) \neq \mathrm{c}\left(\mathrm{u}_{\mathrm{i}}\right) \neq \mathrm{c}\left(\mathrm{w}_{\mathrm{i}}\right)$. The coloring $\mathrm{c}$ is a proper coloring.

Next claim that $\mathrm{c}$ is harmonious coloring. It is clear that each vertex receive a distinct color at a distance atmost 2 from all other vertices, thus coloring is harmonious.

Now we claim that $\mathrm{c}$ is the minimum number of colors in a harmonious coloring. Suppose not, we have the following cases.

Case (i): The color set $\mathrm{c}\left(\mathrm{v}_{\mathrm{i}}\right), \mathrm{c}\left(\mathrm{u}_{\mathrm{i}}\right)$ and $\mathrm{c}\left(\mathrm{w}_{\mathrm{i}}\right)$ contains $3 \mathrm{n}+1$ colors. If we assign $3 \mathrm{n}$ colors, then the color pair will not be distinct which contradict the definition of harmonious colors.

Case (ii): The neighbours of $u_{i}, v_{i}$ and $w_{i}$ are given same color, then the color pair repeats which is a contradiction to the definition of harmonious coloring.

Hence the minimum number of colors in a harmonious coloring for central graph of diamond snake is $3 n+5$, where $3 n$ is the maximum degree in $C\left[D_{n}\right]$.

Hence $\chi_{h}(G)=\Delta\left\{C\left[D_{n}\right]\right\}+5$. 


\section{Illustration for the above theorem:}

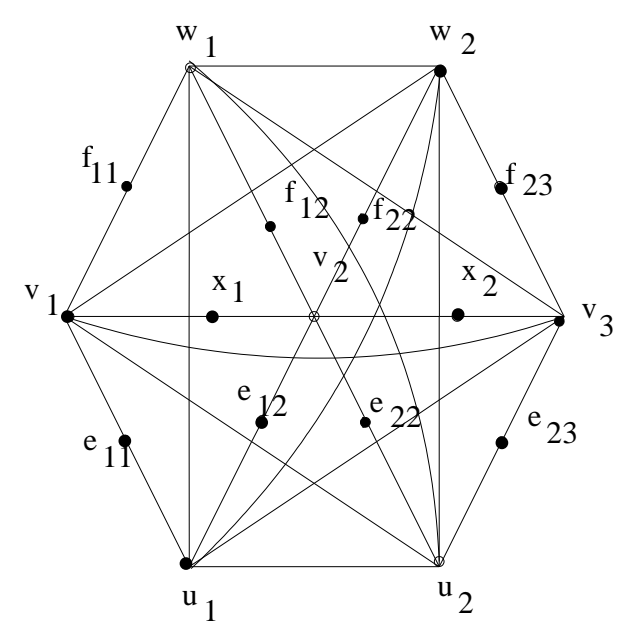

Figure 8: Central graph of a diamond graph $\left(\mathrm{C}\left[\mathrm{D}_{2}\right]\right)$

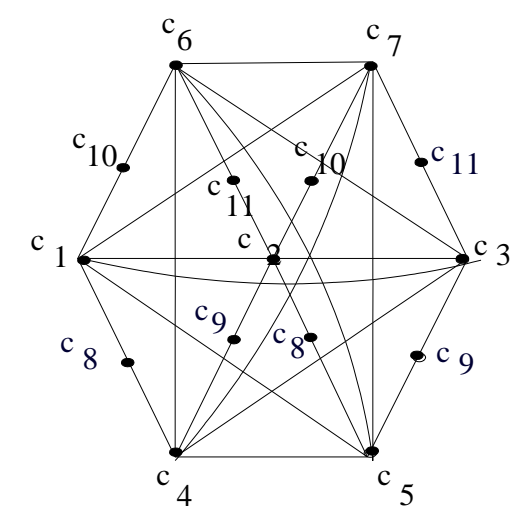

Figure 9: $\chi_{\mathrm{h}}\left(\mathrm{C}\left[\mathrm{D}_{2}\right]\right)=11$

\section{References}

[1] K. J. Edwards and C. J. H. Diarmid, New upper boundson harmonious colorings, Journal of Graph Theory, Vol. 18, pages 257-267, 1994.

http://dx.doi.org/10.1002/jgt.3190180305

[2] K. J. Edwards, The harmonious chromatic number and the achromatic number, in Surveys in Combinatorics, 1997 (Invited papers for 16th British Combinatorial Conference) (ed. R. A. Bailey), LMS Lecture Notes, 241, Cambridge University Press, Cambridge, pages 13 - 47, 1997.

http://dx.doi.org/10.1017/cbo9780511662119.003 
[3] K. J. Edwards, A new upper bound for the harmonious chromatic number, Journal of Graph Theory, Vol. 29, pages 257 - 261, 1998.

http://dx.doi.org/10.1002/(sici)1097-0118(199812)29:4<257::aid-jgt4>3.0.co;2-n

[4] J. E. Hopcrof and Krishnamoorthy, On the harmonious coloring of graph, SAM.J.Algebraic and Discrete Methods, vol 4, pages 306-311, 1983.

http://dx.doi.org/10.1137/0604032

[5] K. Thilagavathi, D. Nidha, N. Roopoesh, On harmonious coloring of $C\left(W_{n}\right)$ and $C\left(F_{m, n}\right)$, Electronics Notes in Discrete Mathematics vol. 33, pages 95-99, 2009. http://dx.doi.org/10.1016/j.endm.2009.03.014

Received: December 9, 2014; Published: January 12, 2015 